\begin{tabular}{|c|l|}
\hline Title & Thermal degradation of anodic niobia on niobium and oxygen-containing niobium \\
\hline Author(s) & $\begin{array}{l}\text { Habazaki, H.; Y amasaki, M.; Ogasawara, T.; Fushimi, K.; Konno, H.; Shimizu, K.; Izumi, T.; Matsuoka, R.; Skeldon, } \\
\text { P.; Thompson, G. E. }\end{array}$ \\
\hline Citation & $\begin{array}{l}\text { Thin Solid Films, 516(6), 991-998 } \\
\text { https://doi.org/10.1016/.tsf.2007.06.127 }\end{array}$ \\
\hline Issue Date & 2008-01-30 \\
\hline Doc URL & http://hdl.handle.net/2115/33038 \\
\hline Type & article (author version) \\
\hline File Information & habasaki.pdf \\
\hline
\end{tabular}

Instructions for use 


\section{Thermal Degradation of Anodic Niobia on Niobium and Oxygen-Containing Niobium}

H. Habazaki ${ }^{1 *}$, M. Yamasaki ${ }^{2}$, T. Ogasawara ${ }^{1}$, K. Fushimi ${ }^{1}$, H. Konno ${ }^{1}$, K. Shimizu ${ }^{3}$, T. Izumi ${ }^{4}$, R. Matsuoka ${ }^{4}$, P. Skeldon ${ }^{5}$ and G. E. Thompson ${ }^{5}$

${ }^{1}$ Graduate School of Engineering, Hokkaido University, N13-W8, Sapporo 060-8628, Japan ${ }^{2}$ Shock Wave and Condensed Matter Research Center, Kumamoto University, 2-39-1, Kurokami, Kumamoto 860-8555, Japan

${ }^{3}$ University Chemical Laboratory, Keio University, 4-1-1 Hiyoshi, Yokohama 223-8521, Japan

${ }^{4}$ Cabot Supermetals, K.K., 111 Nagayachi, Kawahigashi-machi, Kawanuma-gun, Fukushima-pref. 969-3431, Japan

${ }^{5}$ Corrosion and Protection Centre, School of Materials, The University of Manchester, P.O.Box 88, Manchester, M60 1QD, UK

*Corresponding author: Tel. \& fax +81-11-706-6575; e-mail habazaki@eng.hokudai.ac.jp (H. Habazaki) 


\section{Abstract}

Thermal treatment of anodized niobium and oxygen-containing niobium has been carried out to elucidate the thermal degradation mechanism of niobium capacitors and to clarify the influence of oxygen dissolved in niobium on thermal degradation. The capacitance and leakage current of the anodized specimens increase with thermal treatment above $423 \mathrm{~K}$ in air, although the oxygen content in the substrate has no significant effect up to $523 \mathrm{~K}$. At increased temperatures, the changes in capacitance and leakage current are suppressed with increasing oxygen content. The anodic film formed on the $\mathrm{Nb}-50$ at $\% \mathrm{O}$ substrate thickens significantly during thermal treatment at $623 \mathrm{~K}$ in air, while only a slight reduction of the thickness is evident for those on the niobium and $\mathrm{Nb}-20$ at $\% \mathrm{O}$ substrates. In contrast, vacuum thermal treatment at $623 \mathrm{~K}$ causes thinning of the anodic film on niobium, with evidently no change in the film thickness on the $\mathrm{Nb}-50$ at $\% \mathrm{O}$ substrate. These are interpreted in terms of oxygen diffusion from the anodic film to the substrate as well as thermal oxide growth.

Keywords; anodic oxidation, dielectric properties, niobium oxide, heat treatment, TEM, GDOES, XPS 


\section{Introduction}

Niobium is a promising alternative to tantalum for solid electrolytic capacitor generation because of its high natural abundance and the relatively high permittivity of dielectric niobium oxide, $\mathrm{Nb}_{2} \mathrm{O}_{5},(\sim 42)$ compared with anodic tantalum oxide $(\sim 27)$. Thus, solid electrolytic niobium capacitors of high capacity and low cost may be realised. However, the poor reliability of niobium capacitors, due to low thermal stability and the susceptibility for crystallization of the amorphous dielectric oxide[1, 2], need to be addressed.

Niobium monoxide, $\mathrm{NbO}$, with metallic conductivity is also a capacitor material of potential. However, the formation of dielectric niobium oxide on $\mathrm{NbO}$ substrates and its dielectric properties, as well as the reliability of $\mathrm{NbO}$ capacitors await detailed understanding. The present authors have examined the influence of oxygen in niobium on the growth [3] and field crystallization [4] of anodic niobium oxide. The anodic niobium oxide develops on niobium by simultaneous growth at the metal/film and film/electrolyte interfaces by migration of oxygen ions inward and niobium ions outward respectively. About $30 \%$ of the film material is formed at the film/electrolyte interface, which decreases with increase of the oxygen content in niobium up to $\sim 50$ at $\%$; interestingly, the transport numbers of cations and anions in growing anodic niobium oxide are independent of the oxygen content in the substrate [3]. The capacitances of the anodic oxide films formed under a particular anodizing condition are similar, irrespective of the substrate composition. A beneficial effect of oxygen is revealed in the suppression of field crystallization [4], that occurs during growth of anodic oxide films on niobium [5-8], as well as tantalum [9-11], at increased electrolyte temperatures of more than $333 \mathrm{~K}$ and at relatively high formation voltages. Field crystallization is delayed by the addition of 20 at $\%$ oxygen, and no crystallization is observed for films formed on the Nb-50 at $\% \mathrm{O}$ substrate [4].

Here, the influence of oxygen in niobium on the thermal stability of anodized 
niobium, which is an important factor in the development of capacitors, is reported. Thermal treatments of the anodized niobium and oxygen-containing niobium have been carried out at temperatures up to $623 \mathrm{~K}$, largely in air. Additionally, to assist understanding of the thermal degradation behaviour, vacuum thermal treatment has also been performed.

\section{Experimental details}

Niobium and $\mathrm{Nb}-(20$ and 50) at\% $\mathrm{O}$ films, approximately $300 \mathrm{~nm}$ thick, were deposited by sputtering $99.9 \%$ niobium in either argon or a mixture of argon and oxygen at $\sim 0.1 \mathrm{~Pa}$, using magnetron sputtering enhanced with a radiofrequency plasma source to increase the plasma density. The films were deposited onto glass plates, silicon wafers and electropolished and anodized aluminum sheets, all with relatively flat surfaces. The deposited films were of single phase material, with the niobium and $\mathrm{Nb}-20$ at $\% \mathrm{O}$ films displaying bcc structures and the $\mathrm{Nb}-50$ at $\% \mathrm{O}$ film being amorphous. The anodizing behaviour of the amorphous $\mathrm{Nb}-50 \mathrm{at} \% \mathrm{O}$ film was similar to that of the crystalline $\mathrm{NbO}$ compound [4].

The deposited films were anodized at a current density of $50 \mathrm{~A} \mathrm{~m}^{-2}$ to selected voltages, with and without current decay, in stirred $0.1 \mathrm{~mol} \mathrm{dm}^{-3}$ phosphoric acid electrolyte at $293 \mathrm{~K}$. The anodic film grows at a formation ratio of $2.1 \mathrm{~nm} \mathrm{~V}^{-1}$ to selected voltage for all three films. A platinum sheet was used as a counter electrode. The thermal treatment of the anodized specimens was carried out in air or vacuum $\left(\sim 10^{-3} \mathrm{~Pa}\right)$ at several temperatures for $3.6 \mathrm{ks}$. The capacitances of the anodic films, before and after thermal treatment, were determined by electrochemical impedance spectroscopy using a Princeton Applied Research $263 \mathrm{~A}$ potentiostat/galvanostat and 1025 frequency response detector system in $0.1 \mathrm{~mol} \mathrm{dm}$ phosphoric acid electrolyte at $1.5 \mathrm{~V}$ vs SCE with an ac amplitude of $20 \mathrm{mV}$. The leakage current density, defined as the current density recorded after application of $70 \%$ of the formation voltage for $120 \mathrm{~s}$, was also measured in $0.1 \mathrm{~mol} \mathrm{dm}^{-3}$ phosphoric acid. 
Electron transparent sections of the anodized specimens, before and after thermal treatment, were generated using a Leica Ultracut S ultramicrotome. The encapsulated specimens were trimmed initially with glass knives, and suitably thin sections, about $10 \mathrm{~nm}$ thick, were prepared using a diamond knife. The sections were observed using a JEOL JEM-2010 transmission electron microscope operating at $200 \mathrm{kV}$. Depth profiling analyses of the anodic films were carried out by GDOES using a Jobin-Yvon 5000 RF instrument in an argon atmosphere of $898 \mathrm{~Pa}$ by applying radio-frequency of $13.56 \mathrm{MHz}$ and power of $40 \mathrm{~W}$. Light emissions of characteristic wavelengths were monitored throughout the analysis with a sampling time of $0.01 \mathrm{~s}$ to obtain depth profiles. The wavelengths of the spectral lines used were $313.079,178.287$ and $130.217 \mathrm{~nm}$ for niobium, phosphorus and oxygen respectively. The signals were detected from a circular area of approximately $4 \mathrm{~mm}$ diameter. Further, changes in the thicknesses of the anodic films after thermal treatment at several temperatures were determined from the measurements of optical reflection spectra [12], using a JASCO V-550 UV-vis spectrometer; the refractive index of niobium oxide used for calculations is that reported in the literature [13]

In order to probe phenomena occurring in the region of the metal/film interface region during thermal treatment, XPS spectra of the as-deposited specimens were also measured after heating at 523 and $623 \mathrm{~K}$ in the XPS chamber at high vacuum of $\sim 2 \times 10^{-6} \mathrm{~Pa}$. The spectra were obtained using a Thermo Electron, Sigma Probe system with Al Ka excitation $(\mathrm{h} v=1486.6 \mathrm{eV})$. Binding energies of the photoelectrons were calibrated using the method described elsewhere [14].

\section{Results and Discussion}

\section{Formation of anodic oxide}

Figure 1 shows the current decay curves for the niobium and two $\mathrm{Nb}-\mathrm{O}$ substrates 
after anodizing at a constant current density to $50 \mathrm{~V}$ in phosphoric acid electrolyte; both current density and anodizing time are plotted on logarithmic scales. The time origin of Fig. 1 has been set to the point when the formation voltage just reached $50 \mathrm{~V}$. For all three specimens, the current density decreased approximately linearly with anodizing time on the double logarithmic plot, with a slope close to -1 . Thus, the growth of the anodic films follows high field kinetics. Reduced current densities are observed for specimens with increased oxygen contents. However, the capacitances of the anodic films formed on the three substrates before thermal treatment, being $3.0 \mathrm{mF} \mathrm{m}^{-2}$, do not depend upon the oxygen content, implying similar thicknesses of the anodic film materials. The compositions of the anodic films were also similar irrespective of the oxygen content in the niobium [3]. However, as shown later, differences in the depth distribution of phosphorus species incorporated into in the anodic films from the electrolyte arise.

\subsection{Thermal degradation of dielectric properties}

As reported previously for anodized niobium specimens[15], the Bode plots of all specimens, before and after thermal treatment at the selected temperatures, revealed that the impedance changed linearly over a wide range of frequency with a slope of approximately -1 . Such behaviour is typical of dielectric materials. Changes in the capacitance and leakage current with thermal treatment temperature for the anodic films formed at $50 \mathrm{~V}$ for $7.2 \mathrm{ks}$ are displayed in Fig. 2. Both the capacitance and the leakage current do not change significantly up to $423 \mathrm{~K}$; at increased thermal treatment temperatures, marked increases in capacitance and leakage current are evident.

The marked increase in the capacitance above $423 \mathrm{~K}$ is considered to be associated mainly with changes in the semiconducting properties of the anodic niobium oxide, since little, or no, changes in the structure and thickness of the anodic oxide are evident for thermal 
treatment up to $573 \mathrm{~K}$ [15]. The anodic niobium oxide is an n-type semiconductor, with a band gap of $3.4 \mathrm{eV}$ [16]. It is known that the capacitance of anodic niobium oxide is dependent upon bias potential. The dependence has been interpreted in terms of the change in the thickness of a space-charge layer [17]. The bias potential dependence of the capacitance of the anodic niobium oxide was enhanced after thermal treatment [15]. Thus, the increased capacitance after thermal treatment may be associated with a reduced space-charge layer thickness in the anodic niobium oxide, not due to a change in permittivity.

The increase in the leakage current density above $473 \mathrm{~K}$ may result from the development of flaws in the anodic oxide films during thermal treatment, although direct evidence is awaited. Little or no influence of oxygen content in niobium on both the capacitance and leakage current is evident for temperatures up to $523 \mathrm{~K}$. Further increase in the capacitance as well as leakage current at increased temperatures is suppressed by an increase in the oxygen content in niobium. In order to understand the different capacitance and leakage current of the specimens of various oxygen contents after thermal treatment at $623 \mathrm{~K}$, characterization of the anodized specimens has been carried out before and after thermal treatment.

\subsection{Characterization of anodized specimens after thermal treatment}

Changes in thicknesses of the anodic films, estimated from the reflection spectra, with thermal treatment temperature are shown in Figure 3. It is evident that the change in film thickness is largely dependent upon the oxygen content in niobium. For the oxygen-free niobium, the thickness of the anodic film is almost constant up to $473 \mathrm{~K}$; with further increase in temperature, the thickness reduces by $3-4 \mathrm{~nm}$. In contrast, marked thickening, up to $\sim 30 \mathrm{~nm}$, of the anodic film occurs on the $\mathrm{Nb}-50$ at $\% \mathrm{O}$ substrate above $523 \mathrm{~K}$. The $\mathrm{Nb}-20$ at $\% \mathrm{O}$ substrate displayed the lowest change in film thickness, with thinning of only $2 \mathrm{~nm}$ 
determined at $623 \mathrm{~K}$.

Marked thickening of the anodic film formed on the $\mathrm{Nb}-50$ at $\% \mathrm{O}$ substrate after thermal treatment at $623 \mathrm{~K}$ was confirmed by direct TEM observations of ultramicrotomed sections. The as-formed anodic film developed on the $\mathrm{Nb}-50$ at $\% \mathrm{O}$ substrate with relatively flat and parallel substrate/film and film/electrolyte interfaces (Fig. 4 (a)); the substrate appears at the bottom of the micrograph. The generally featureless appearance of the anodic film indicates an amorphous structure. The selected area diffraction patterns also revealed that both the anodic film and the $\mathrm{Nb}-50 \mathrm{at} \% \mathrm{O}$ substrate are amorphous. The thickness of the anodic film is $210 \mathrm{~nm}$, which increases to $233 \mathrm{~nm}$ after thermal treatment (Fig. 4(c)). The amorphous structure of the anodic film after thermal treatment is evident from this micrograph. In addition to the thickness of the anodic film, the appearance of the substrate/film interface region changes after thermal treatment; the substrate/film interface reveals sharp and distinct contrast before thermal treatment (Figs. 4(a) and (b)) whereas, after thermal treatment at 623 $\mathrm{K}$, the interface becomes less distinct (Figs. 4(c) and (d)). This change may arise from the formation of intermediate oxide layer, such as $\mathrm{NbO}_{2}$, between the anodic film and the $\mathrm{Nb}-50$ at $\% \mathrm{O}$ substrate after thermal treatment.

GDOES depth profiles of the anodic films on the niobium and $\mathrm{Nb}-50$ at $\% \mathrm{O}$ substrates, before and after thermal treatment at $623 \mathrm{~K}$ (Fig. 5), also support the results of Fig. 3. The time required to sputter through the anodic film, corresponding to the film thickness, increases for the $\mathrm{Nb}-50$ at $\% \mathrm{O}$ substrate after the thermal treatment, whereas little change in the sputtering time is revealed for the niobium substrate. In Fig. 5, the wavy profiles of niobium in the anodic films arise from optical interference of light emitted from the respective element [15]. Phosphorus species, incorporated from electrolyte into the anodic films, are located in approximately the outer one-half of the film thickness of the anodic film formed on the niobium substrate. In contrast, the distribution of the phosphorus species in the anodic 
film formed on the $\mathrm{Nb}-50$ at $\% \mathrm{O}$ substrate extend to only one-third of the film thickness. The different distributions of phosphorus species arise from incorporation of oxygen species from the substrate in addition to the electrolyte for the $\mathrm{Nb}-50$ at $\% \mathrm{O}$ specimen. No influence of oxygen content in the substrate on the transport numbers of cations and anions was confirmed in previous marker studies [3].

\subsection{Thermal treatment in vacuum}

In order to gain further insight into the different behaviours of the anodized specimens with various oxygen contents during thermal treatment in air, thermal treatment was also carried out in vacuum at $623 \mathrm{~K}$. The changes in the thickness of the anodic films, before and after the thermal treatment, for the niobium and $\mathrm{Nb}-50 \mathrm{at} \% \mathrm{O}$ specimens were evaluated from the GDOES elemental depth profiles (Fig. 6). Thinning of the anodic film on niobium after vacuum thermal treatment is evident from the reduced sputtering time to reach the metal substrate after thermal treatment (Fig. 6(a)); this contrasts with the insignificant change in film thickness before and after thermal treatment in air (Fig. 5(a)). For the Nb-50 at $\% \mathrm{O}$ specimens, vacuum thermal treatment induces little change in thickness of the anodic film (Fig. 6(b)), although marked thickening of the anodic film occurs during thermal treatment in air. Thus, the environment employed for thermal treatment influences significantly the changes in thicknesses of the anodic films.

XPS measurements of the as-deposited niobium and $\mathrm{Nb}-50$ at $\% \mathrm{O}$ specimens, without prior formation of anodic films, were performed during in-situ thermal treatment at $523 \mathrm{~K}$ and $623 \mathrm{~K}$ for $3.6 \mathrm{ks}$ in the high vacuum XPS chamber of $\sim 2 \times 10^{-6} \mathrm{~Pa}$. Figure 7 shows $\mathrm{Nb} 3 \mathrm{~d}$ and $\mathrm{O} 1 \mathrm{~s}$ spectra for the as-deposited substrates before and after thermal treatment; before thermal treatment, the $\mathrm{Nb} 3 \mathrm{~d}$ spectrum (Fig. 7(a)) comprises a strong doublet at 207.7 and $210.5 \mathrm{eV}$ corresponding to $\mathrm{Nb}^{5+}$ species, probably $\mathrm{Nb}_{2} \mathrm{O}_{5}$, in addition to metallic niobium 
peaks at 202.3 and $205.2 \mathrm{eV}$ [18]. The O 1s spectrum (Fig. 7(b)) depicts a major peak at 530.9 $\mathrm{eV}$ with a shoulder at about $533.0 \mathrm{eV}$, which may be assigned to loosely bound water. The shoulder disappears after thermal treatment at both temperatures. The $\mathrm{O} 1 \mathrm{~s}$ peak intensity also decreased after thermal treatment, but no change in the peak binding energy is evident.

In contrast to the $\mathrm{O} 1 \mathrm{~s}$ spectra, the peak binding energies of the $\mathrm{Nb} 3 \mathrm{~d}$ spectra change significantly with thermal treatment temperature, suggesting a change in the chemical state of niobium species. After the thermal treatments at $523 \mathrm{~K}$ and $623 \mathrm{~K}$, the strong doublet peaks shift $4.5 \mathrm{eV}$ toward lower binding energy, i.e., binding energies corresponding to $\mathrm{Nb}^{+}$species, such as $\mathrm{Nb}_{2} \mathrm{O}$ [19]. The peaks of metallic niobium appear as shoulders, with their relative intensities being enhanced after thermal treatments. The XPS results obtained for the niobium substrate in this work agree with a previous study [19], which revealed a reduction of the air-formed $\mathrm{Nb}_{2} \mathrm{O}_{5}$ to $\mathrm{Nb}_{2} \mathrm{O}$ without significant change of the oxide layer thickness during thermal treatment at $523 \mathrm{~K}$ in the high vacuum XPS chamber. The reduction of $\mathrm{Nb}_{2} \mathrm{O}_{5}$ occurs as a consequence of oxygen diffusion to the bulk niobium substrate. The absence of oxygen species released to the vacuum atmosphere at temperatures up to $1023 \mathrm{~K}$ was confirmed by mass spectroscopy of the niobium substrate supporting an anodic oxide of $33 \mathrm{~nm}$ thickness [18].

When the as-deposited $\mathrm{Nb}-50$ at $\% \mathrm{O}$ was thermally treated in the XPS chamber, the reduction behaviour of the air-formed $\mathrm{Nb}_{2} \mathrm{O}_{5}$ was different from that on the oxygen-free niobium substrate (Fig. 8). Before thermal treatments, the $\mathrm{Nb} 3 \mathrm{~d}$ and $\mathrm{O} 1 \mathrm{~s}$ spectra for the as-deposited $\mathrm{Nb}-50$ at $\% \mathrm{O}$ are similar to those for the as-deposited niobium; however, the $\mathrm{Nb}$ $3 \mathrm{~d}_{5 / 2}$ peak binding energy of the substrate is $2.1 \mathrm{eV}$ higher than that of oxygen-free niobium. The binding energy of the $\mathrm{Nb}-50 \mathrm{at} \% \mathrm{O}$ substrate is in agreement with that of $\mathrm{NbO}[18]$. After thermal treatment at $523 \mathrm{~K}, \mathrm{Nb}_{2} \mathrm{O}_{5}$ still remains, but an additional doublet corresponding to $\mathrm{NbO}_{2}$ is displayed (Fig. 8(a)). $\mathrm{NbO}$ dominates after thermal treatment at $623 \mathrm{~K}$, but the tailing 
of the doublet peaks towards higher binding energy suggests the presence of small amounts of $\mathrm{NbO}_{2}$ and $\mathrm{Nb}_{2} \mathrm{O}_{5}$. The reduction of $\mathrm{Nb}_{2} \mathrm{O}_{5}$ to $\mathrm{NbO}$ on the $\mathrm{Nb}-50$ at $\% \mathrm{O}$ substrate indicates that the substrate with supersaturated oxygen can dissolve further oxygen during thermal treatment in vacuum. However, from comparison of Figs. 7 and 8, it is evident that oxygen dissolves more readily into the oxygen-free niobium substrate.

3.5 Qualitative explanation of the change in anodic oxide during thermal treatment in air and vacuum

The XPS results clearly demonstrate that oxygen diffusion occurs from the surface oxide layer to the underlying oxygen-free and oxygen-supersaturated niobium substrates at increased temperatures of 523-623 K. Oxygen dissolution into the substrate proceeds more readily for the oxygen-free niobium. A previous kinetic study of King et al. revealed that the oxygen dissolution process is controlled by the interfacial reaction between the oxide layer and metal substrate, not by the movement of transport species in the oxide film [18]. Supersaturated oxygen in niobium may reduce the high reactivity of niobium with oxygen in $\mathrm{Nb}_{2} \mathrm{O}_{5}$ layer such that the interfacial reaction is relatively slow for the $\mathrm{Nb}-50$ at $\% \mathrm{O}$ substrate. The different interfacial reactivity of the niobium and $\mathrm{Nb}-50$ at $\% \mathrm{O}$ substrates is a probable cause of the faster thinning of the anodic film on the niobium substrate compared with that on the $\mathrm{Nb}-50$ at $\% \mathrm{O}$ substrate during vacuum thermal treatment at $623 \mathrm{~K}$ (Figs. 9(a) and (b)). The latter anodic film did not show any significant change in the film thickness over thermal treatment of $3.6 \mathrm{ks}$ (Fig. 6).

In contrast, marked thickening of the anodic film on the $\mathrm{Nb}-50$ at $\% \mathrm{O}$ substrate occurs through thermal treatment in air at the same temperature. Thermal oxidation of the substrate should proceed through the anodic film, thickening the oxide film (Fig. 9(d)). From Fig. 5(b), the inner phosphorus-free oxide region thickens after the thermal treatment, while 
little change is found in the outer phosphorus-containing region. Thus, it is likely that the thermal oxide growth proceeds predominantly at the film/substrate interface. This is consistent with the observation that crystalline $\mathrm{Nb}_{2} \mathrm{O}_{5}$ oxide, formed thermally on niobium, grows at the metal/film interface by inward diffusion of oxygen [20]. However, in the present study, the oxide is amorphous after thermal treatment at $623 \mathrm{~K}$. Even if the mechanisms of thermal oxide growth are similar to that of the corresponding anodic oxide growth, $\sim 83 \%$ of the film material is formed at the film/substrate interface [3].

For the anodic film formed on niobium, only a slight thinning of the oxide film is found after the thermal treatment in air at $623 \mathrm{~K}$ (Fig. 3). In this case, thermal oxide growth, contributing to oxide thickening, and oxygen dissolution into substrate, reducing oxide thickness, occur simultaneously, such that the overall change in film thickness becomes less significant. Thermal oxide growth is usually controlled by diffusion of transporting species in an oxide layer; the growth rate should not depend on the oxygen content of the substrates. In this case, the difference in the thickness of the anodic films on the two substrates after thermal treatment in air or vacuum reflects the dissolution rate of oxygen into the substrate. Similar growth rates of the thermal oxides on both substrates are suggested from the fact that difference in the sputtering times of the anodic films on the two substrates after thermal treatment in air is similar to that in vacuum.

In summary, thermal treatment of niobium and oxygen-containing niobium substrates induces oxygen dissolution into the substrate as well as thermal oxide growth at temperatures above $523 \mathrm{~K}$, both of which may influence the semiconducting properties of $\mathrm{Nb}_{2} \mathrm{O}_{5}$ and introduce physical defects, thereby affecting the capacitance and leakage current. Modification of both the anodic film composition and substrate composition appears to be required to improve the thermal stability of anodic films on niobium. Improved thermal stability of the anodic niobium oxide by the addition of silicon to niobium, recently found by 
some of the present authors [21], is consistent with the present findings. Further probing of interfaces between the oxide films and substrates is in progress to provide more detailed mechanism of the thermal degradation.

\section{Conclusions}

Thermal degradation of anodic films formed on niobium and $\mathrm{Nb}-\mathrm{O}$ substrates results in increase of the capacitance and leakage current above $473 \mathrm{~K}$; increase in the oxygen content suppresses such changes at thermal treatment temperatures above $573 \mathrm{~K}$. Thickening of the anodic film on the $\mathrm{Nb}-50 \mathrm{at} \% \mathrm{O}$ substrate, in contrast to the insignificant change in film thickness on the oxygen-free niobium, during thermal treatment, particularly at and above 573 $\mathrm{K}$, contributes partly to this suppression. The anodic film thickens on the $\mathrm{Nb}-50 \mathrm{at} \% \mathrm{O}$ substrate through thermal oxide growth, while oxide growth is compensated by dissolution of oxygen into the substrate for the oxygen-free niobium. For the $\mathrm{Nb}-50$ at $\% \mathrm{O}$ substrate, existing supersaturation with oxygen impedes the dissolution of oxygen during thermal treatment. Due to oxygen dissolution into the substrate, the anodic film on the oxygen-free niobium thins during thermal treatment in vacuum.

\section{Acknowledgments}

Thanks are due to Mr K. Saito of Institute for Materials Research, Tohoku University for the preparation of niobium and $\mathrm{Nb}-\mathrm{O}$ films. The present work was supported in part by a Grant-in-Aid for Scientific Research, No. 16360353 from the Japan Society for the Promotion of Science.

\section{References}

[1] Y. Pozdeev, Qualt. Reliab. Eng. Int. 14 (1998) 79. 
[2] N.F. Jackson, J.C. Hendy, Electrocomponent Sci. Tech. 1 (1974) 27.

[3] H. Habazaki, T. Ogasawara, H. Konno, K. Shimizu, K. Asami, K. Saito, S. Nagata, P. Skeldon, G.E. Thompson, Electrochim. Acta 50 (2005) 5334.

[4] H. Habazaki, T. Ogasawara, H. Konno, K. Shimizu, S. Nagata, K. Asami, K. Takayama, P. Skeldon, G.E. Thompson, J. Electrochem. Soc. 153 (2006) B173.

[5] H. Asoh, H. Odate, S. Ono, J. Surf. Finish. Soc. Jpn. 55 (2004) 952.

[6] K. Nagahara, M. Sakairi, H. Takahashi, S. Nagata, K. Matsumoto, K. Takayama, Y. Oda, J. Surf. Finish. Soc. Jpn. 55 (2004) 943.

[7] D.M. Lakhiani, L.L. Shreir, Nature 188 (1960) 49.

[8] H. Habazaki, T. Ogasawara, H. Konno, K. Shimizu, S. Nagata, P. Skeldon, G.E. Thompson, Corros. Sci. 49 (2007) 580.

[9] D.A. Vermilyea, J. Electrochem. Soc. 104 (1957) 542.

[10] D.A. Vermilyea, J. Electrochem. Soc. 102 (1955) 207.

[11] N.F. Jackson, J. Appl. Electrochem. 3 (1973) 91.

[12] M.P. Pedeferri, B.D. Curto, P. Pedeferri, in: P. Marcus, V. Maurice (eds.), Passivation of Metals and Semiconductors, and Properties of Thin Oxide Layers, Elsevier, Paris, 2006, p. 205.

[13] G.J. Sayag, A. Septier, Thin Solid Films 55 (1978) 191.

[14] K. Asami, J. Electron Spectrosc. Relat. Phenom. 9 (1976) 469.

[15] H. Habazaki, T. Matsuo, H. Konno, K. Shimizu, K. Matsumoto, K. Takayama, Y. Oda, P. Skeldon, G.E. Thompson, Surf. Interface Anal. 35 (2003) 618.

[16] J.W. Shultze, M.M. Lohrengel, Electrochim. Acta 45 (2000) 2499.

[17] A.D. Modestov, A.D. Davydov, J. Electroanal. Chem. 460 (1999) 214.

[18] B.R. King, H.C. Patel, D.A. Gulino, B.J. Tatarchuk, Thin Solid Films 192 (1990) 351.

[19] Q. Ma, R.A. Rosenberg, Appl. Surf. Sci. 206 (2003) 209. 
[20] P. Kofstad, High Temperature Corrosion, 1988, London and New York: Elsevier.

[21] H. Habazaki, T. Matsuo, H. Konno, K. Shimizu, S. Nagata, K. Matsumoto, K. Takayama, Y. Oda, P. Skeldon, G.E. Thompson, Electrochim. Acta 48 (2003) 3519. 
Figure captions

Fig. 1. Current decay curves of the sputter-deposited niobium, $\mathrm{Nb}-20 \mathrm{at} \% \mathrm{O}$ and $\mathrm{Nb}-50 \mathrm{at} \% \mathrm{O}$ substrates during anodizing at a constant voltage of $50 \mathrm{~V}$ in $0.1 \mathrm{~mol} \mathrm{dm}^{-3}$ phosphoric acid electrolyte at $293 \mathrm{~K}$. Initially the substrates were anodized at a constant current density of $50 \mathrm{~A} \mathrm{~m}^{-2}$ to $50 \mathrm{~V}$.

Fig. 2. Changes of the capacitance and leakage current density of the anodic films on the sputter-deposited niobium, $\mathrm{Nb}-20$ at $\% \mathrm{O}$ and $\mathrm{Nb}-50$ at $\% \mathrm{O}$ with temperature of thermal treatment in air. The anodic films were formed at a constant voltage of $50 \mathrm{~V}$ in $0.1 \mathrm{~mol}$ $\mathrm{dm}^{-3}$ phosphoric acid electrolyte at $293 \mathrm{~K}$ for $7.2 \mathrm{ks}$.

Fig. 3. Change in the thickness of the anodic films formed on the sputter-deposited niobium, $\mathrm{Nb}-20$ at $\% \mathrm{O}$ and $\mathrm{Nb}-50$ at $\% \mathrm{O}$ with temperature of thermal treatment in air. The anodic films were formed at a constant voltage of $50 \mathrm{~V}$ in $0.1 \mathrm{~mol} \mathrm{dm}$-3 phosphoric acid electrolyte at $293 \mathrm{~K}$ for $7.2 \mathrm{ks}$.

Fig. 4. Transmission electron micrographs of ultramicrotomed sections of the sputter-deposited $\mathrm{Nb}-50$ at $\% \mathrm{O}$ substrate after anodizing at a constant current density of $50 \mathrm{~A} \mathrm{~m}^{-2}$ to $100 \mathrm{~V}$ without current decay: (a) as-formed; (b) high magnification image of the film/substrate interface region of (a); (c) after thermal treatment in air at $623 \mathrm{~K}$ for $3.6 \mathrm{ks}$; (d) high magnification image of the film/substrate interface region of (c).

Fig. 5 GDOES depth profiles of the anodic films, formed on the sputter-deposited (a) niobium and (b) $\mathrm{Nb}-50$ at $\% \mathrm{O}$ substrates at a constant voltage of $50 \mathrm{~V}$ in $0.1 \mathrm{~mol} \mathrm{dm}^{-3}$ phosphoric acid electrolyte at $293 \mathrm{~K}$ for $7.2 \mathrm{ks}$, before and after thermal treatment in air at $623 \mathrm{~K}$ for $3.6 \mathrm{ks}$.

Fig. 6. GDOES depth profiles of the anodic films, formed on the sputter-deposited (a) niobium and (b) $\mathrm{Nb}-50$ at $\% \mathrm{O}$ substrates at a constant voltage of $50 \mathrm{~V}$ in $0.1 \mathrm{~mol} \mathrm{dm}{ }^{-3}$ phosphoric acid electrolyte at $293 \mathrm{~K}$ for $7.2 \mathrm{ks}$, before and after thermal treatment in 
vacuum at $623 \mathrm{~K}$ for $3.6 \mathrm{ks}$.

Fig. 7. (a) $\mathrm{Nb} 3 \mathrm{~d}$ and (b) $\mathrm{O} 1 \mathrm{~s}$ spectra of the sputter-deposited niobium substrate, before and after thermal treatment in the high vacuum XPS chamber at 523 and $623 \mathrm{~K}$ for $3.6 \mathrm{ks}$.

Fig. 8 (a) $\mathrm{Nb} 3 \mathrm{~d}$ and (b) $\mathrm{O} 1 \mathrm{~s}$ spectra of the sputter-deposited $\mathrm{Nb}-50$ at $\%$ O substrate, before and after thermal treatment in the high vacuum XPS chamber at 523 and $623 \mathrm{~K}$ for 3.6 ks.

Fig. 9 Schematic drawing showing oxygen diffusion during thermal treatment of anodized niobium and $\mathrm{Nb}-50$ at $\% \mathrm{O}$ substrates. 


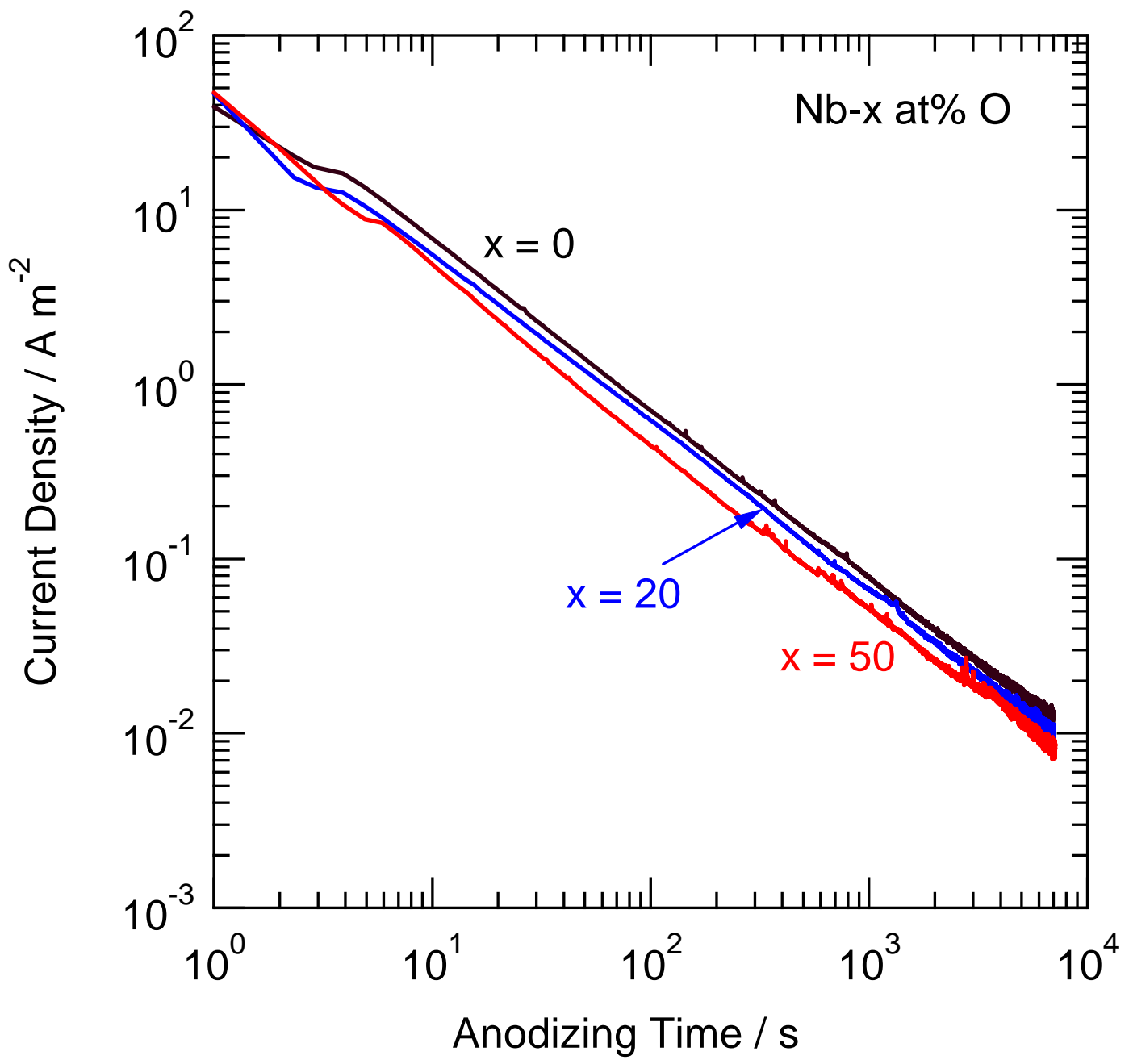

Fig.1 


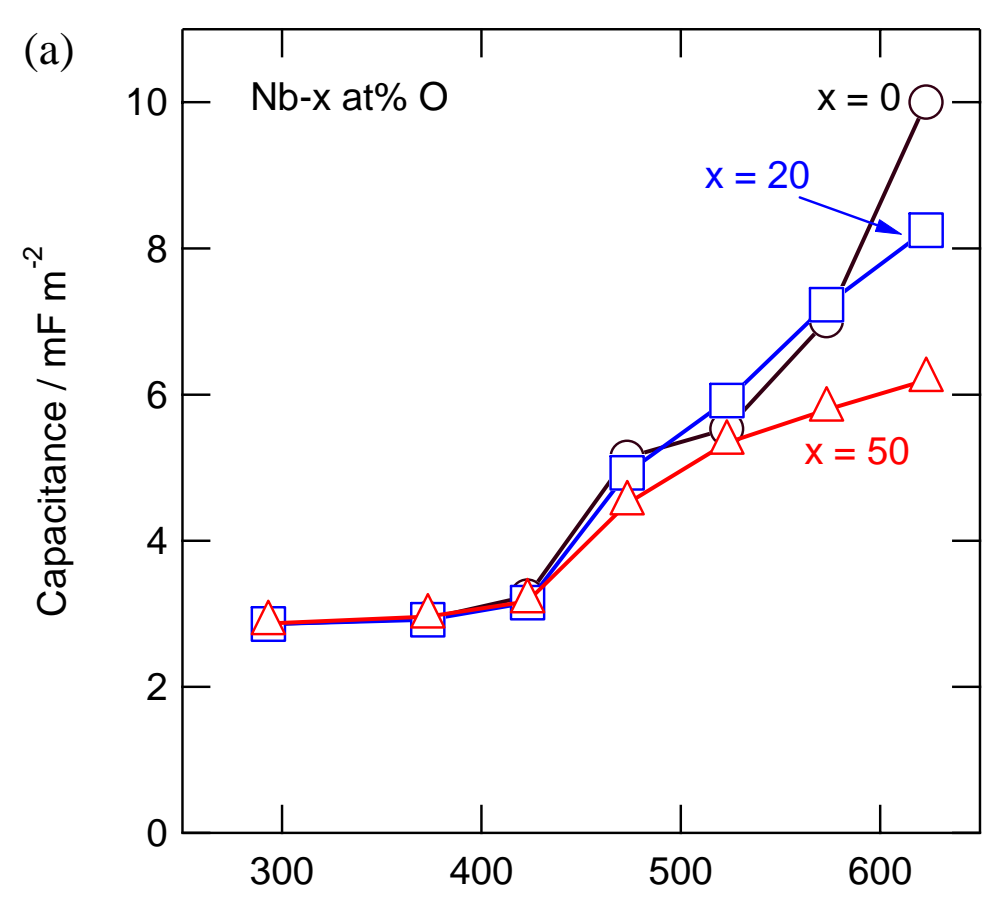

Thermal Treatment Temperature / K

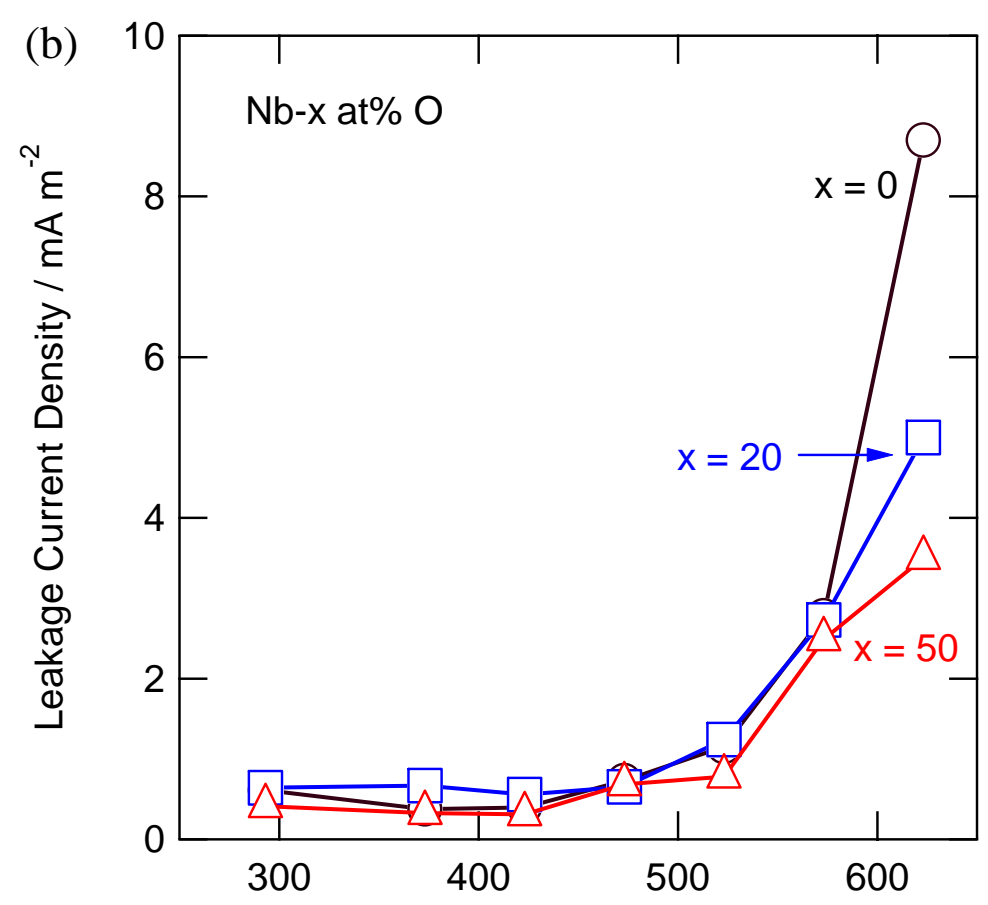

Thermal Treatment Temperature / K

Fig.2 


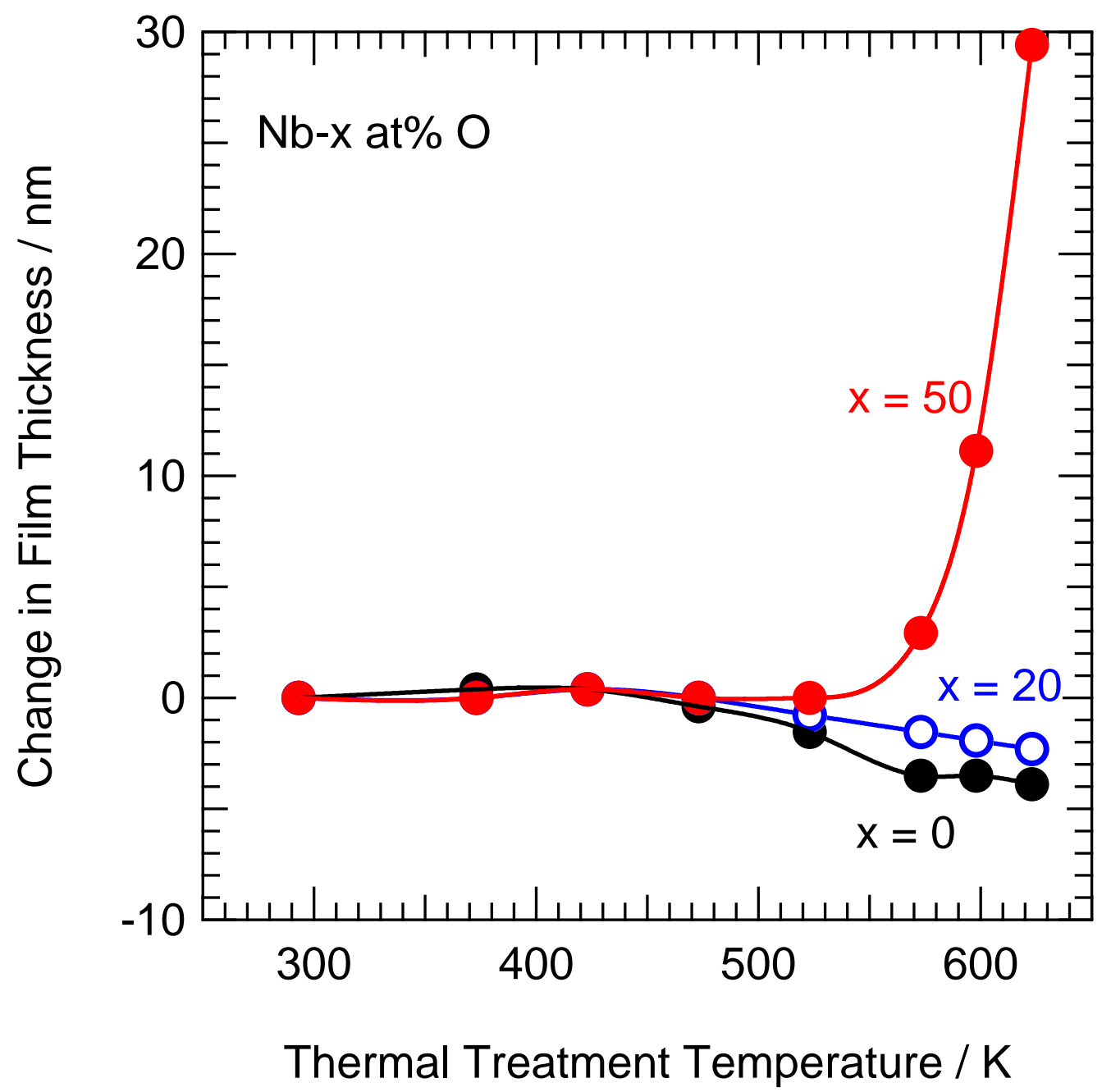

Fig.3 
(a)

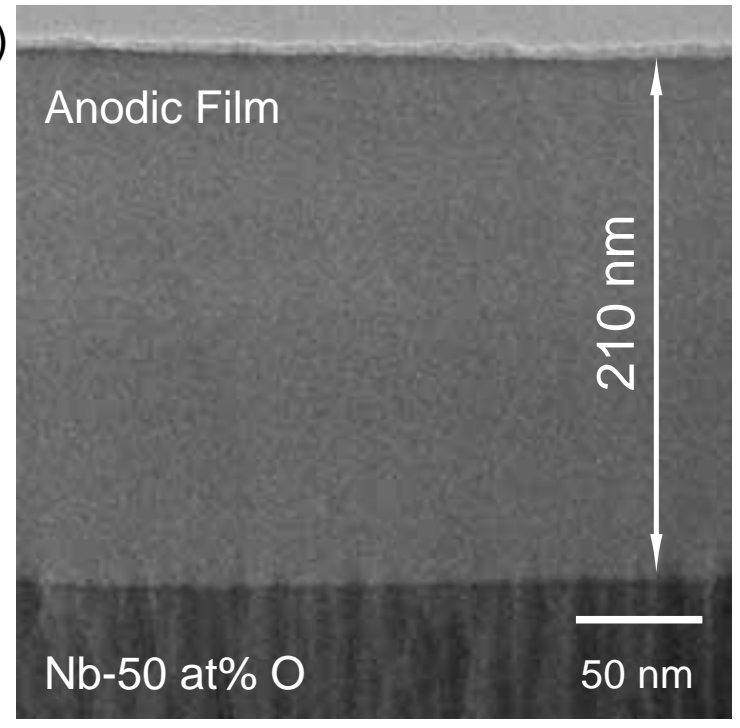

(b)

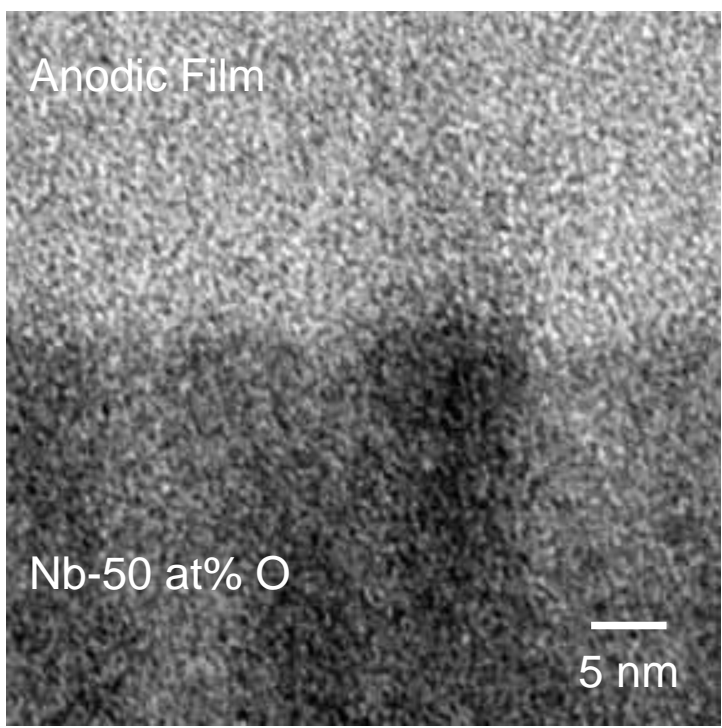

(c)

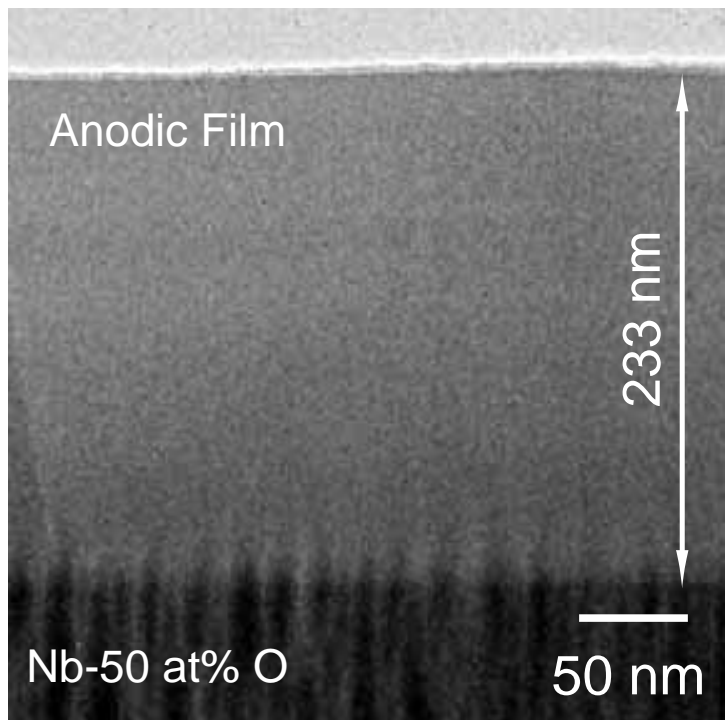

(d)

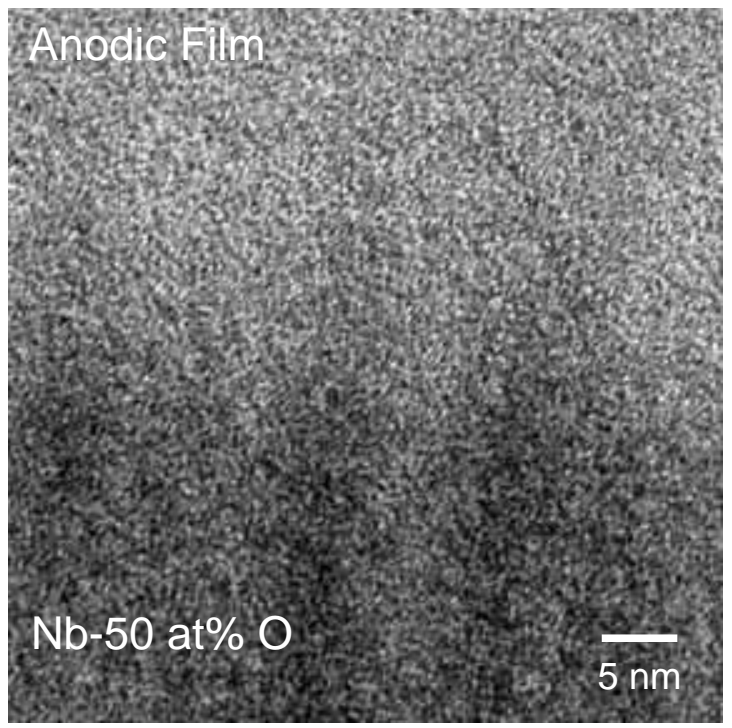

Fig.4 

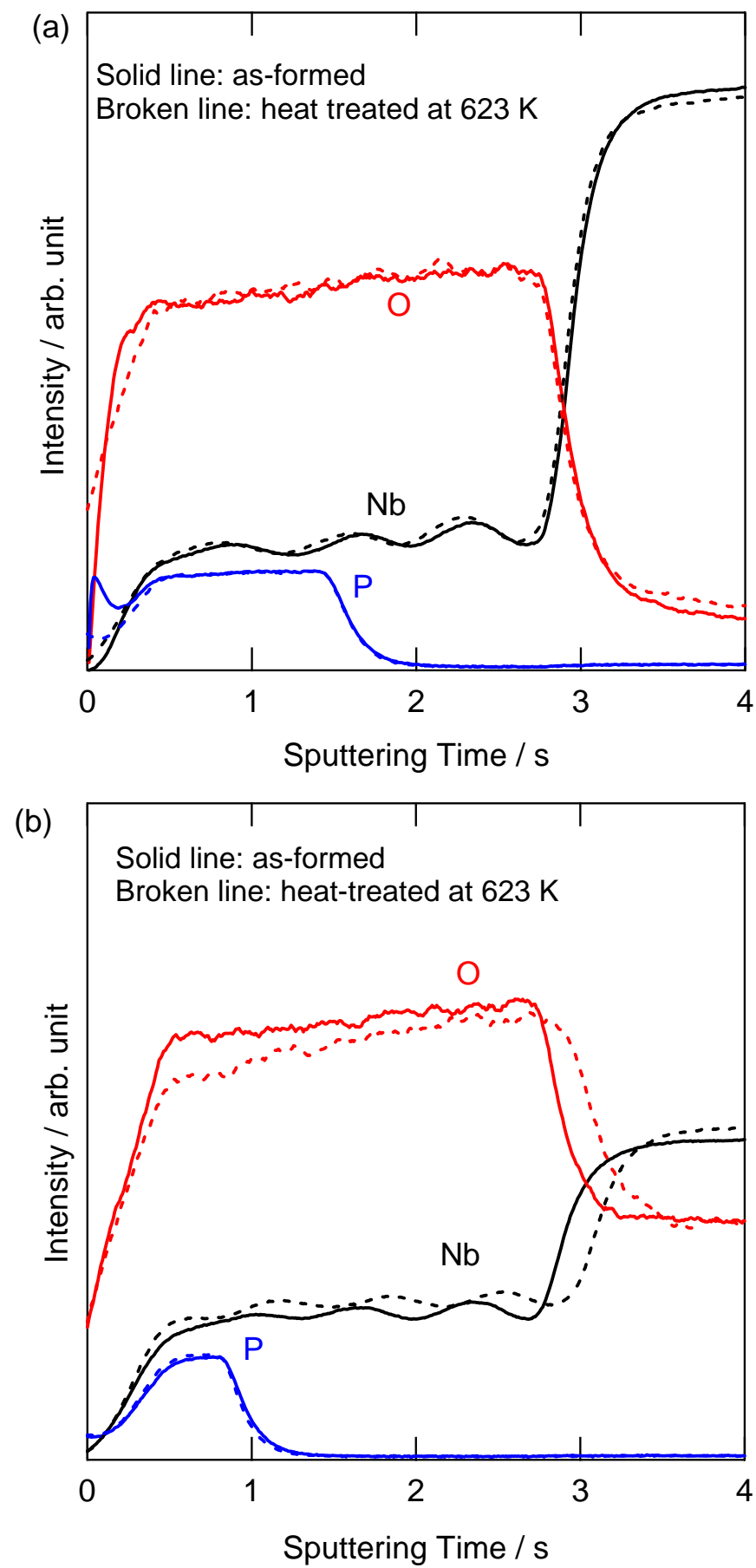

Fig.5 

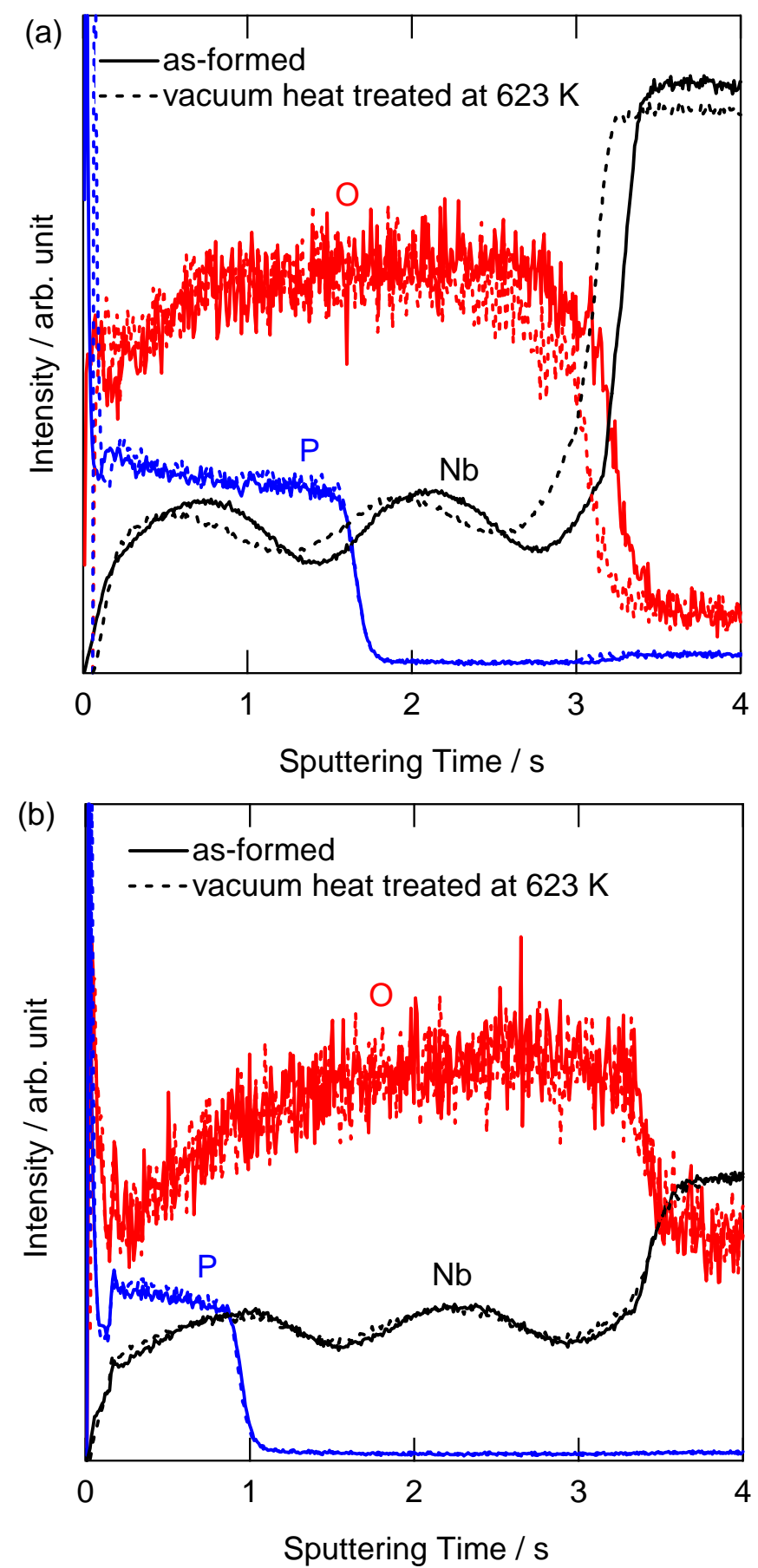

Fig.6 

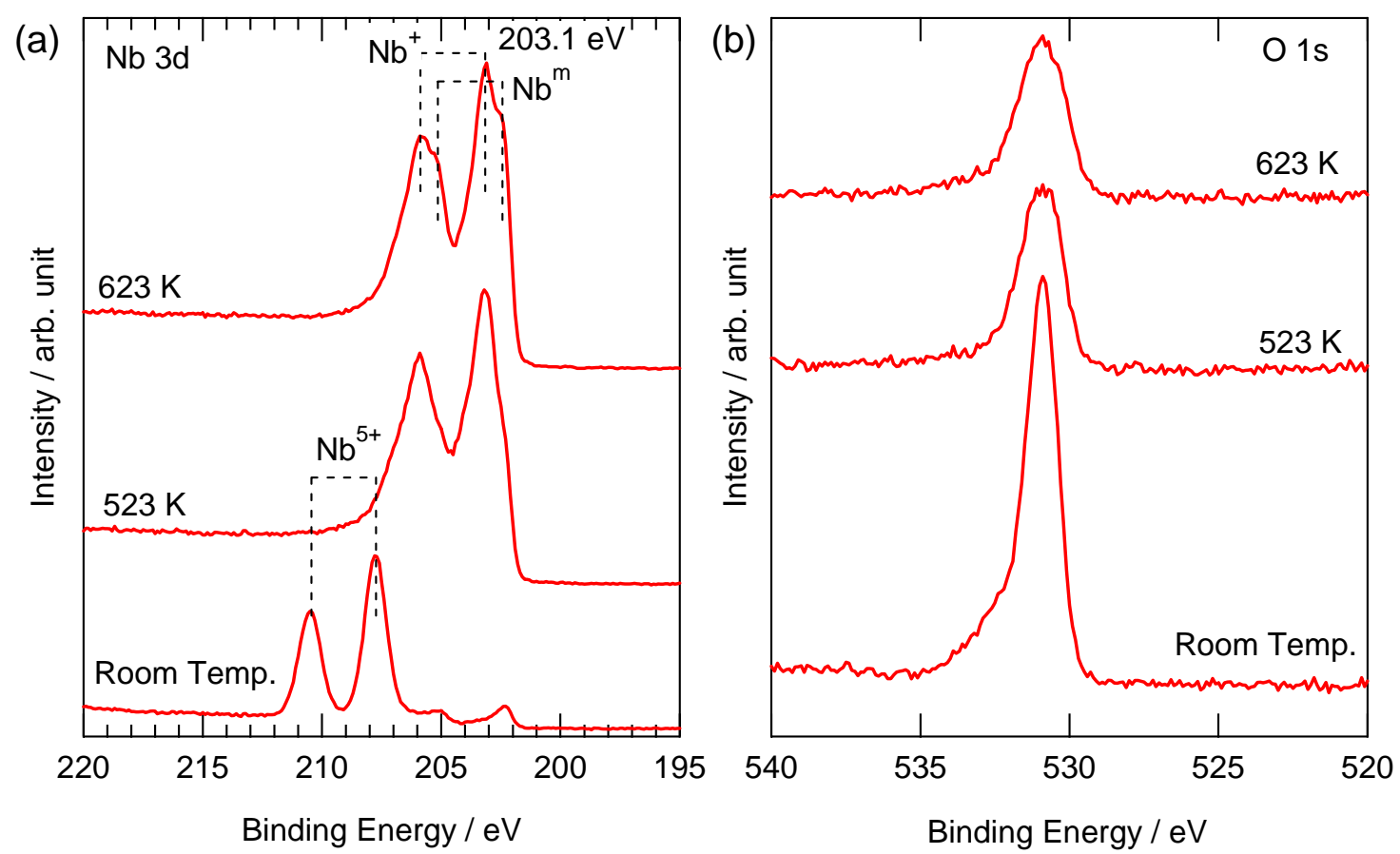

Fig. 7 

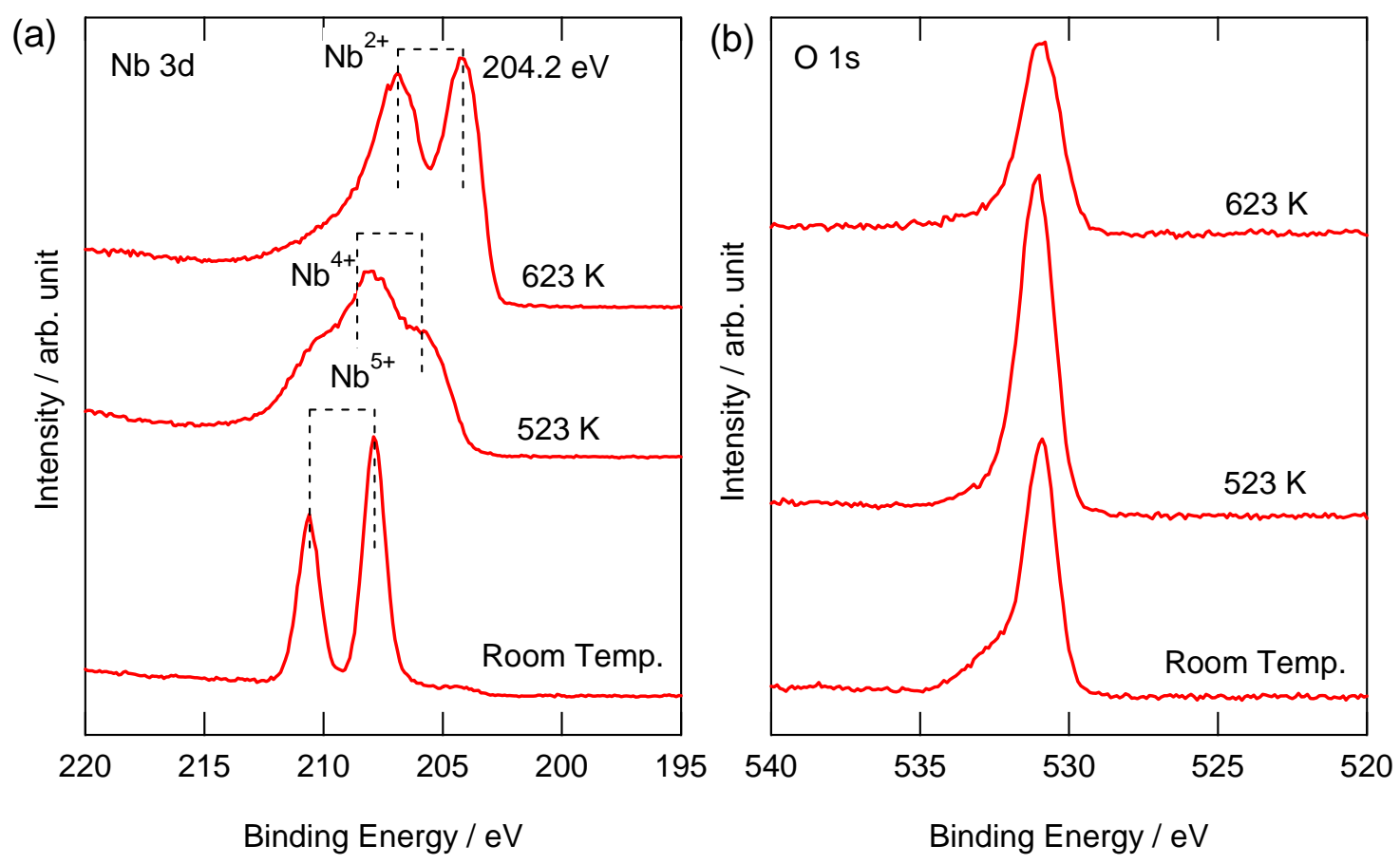

Fig.8 
(a) Thermal treatment in vacuum
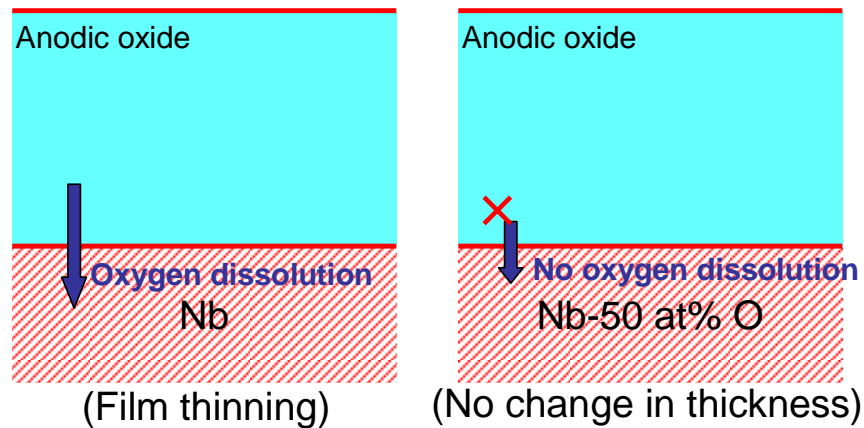

(b) Thermal treatment in air
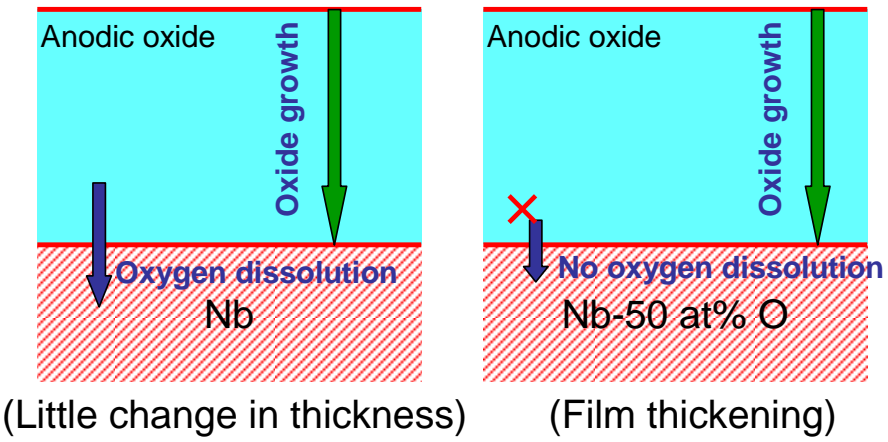

Fig. 9 